\title{
Perceptions of Job Satisfaction Among Arab Female Reporters in Governmental and Non-Governmental TV Stations
}

\author{
Hebatalla El Semary*
}

Mass Communication Department, UAE University, UAE

\begin{abstract}
The prime aim of this study is to find out the Arab Female TV reporters' perception of 'job satisfaction' and to identify the factors which affect job satisfaction of female TV reporters. How ownership and management policy of the TV station could affect job satisfaction among female reporters are among the questions examined in this study. In this research we sought to determine satisfaction with 15 distinct areas of employment (Company policy, Supervision, Relationship w/Peers, Relationship w/boss, Work conditions, Salary, Achievement, Recognition, Work itself, Responsibility, Advancement, Growth, Job Security, Work expectations-Decision making) by using two of the most often used survey instruments (Job Descriptive Index and Job In General) that measure job satisfaction.

A total of 200 questionnaires were to be completed by male and female news reporters who are identified as full-time employees of both governmental and Private Arab TV stations (Dubai Media TV channels \& Middle East Broadcasting Center (MBC) TV channels). Fredrick Herzberg's two factor theory, power distance, and masculinityfemininity theory of Hofstede have been chosen to analyze data as well as variables. Moreover, In-depth interviews were conducted with 10 news personnel in governmental and non-governmental TV Stations to enrich the quantitative data with qualitative evidence.
\end{abstract}

Keywords: Job satisfaction; Management policy; Female TV reporters; Governmental TV stations; Non-governmental TV stations

\section{Introduction}

Job satisfaction is the extent to which one is feeling good and committed to his job. Job satisfaction is important not only for employees but also for employers because it increases productivity and decreases staff turnover. Therefore, it results into making employees devoted and committed to their responsibilities. According to [1]; "The analysis of job satisfaction may give us a number of insights into certain aspects of the labor market."

Clark et al. [1], unlike others, described job satisfaction as " $U$ shaped in age", suggesting that it tends to decline from a moderate level in the first years of employment and keeps rising up to retirement. They investigated that relationship between job satisfaction vis-a-vis age, and their study, which was conducted on a large sample of British employees, provides strong evidence for a U-shaped relationship between age and job satisfaction particularly satisfaction with pay, and satisfaction with the work itself. Moreover, their investigative study showed that a similar U-shaped pattern occurs for employees' context-free mental health, suggesting that both job satisfaction and context-free mental health are affected by non-job factors of life-stage and personal circumstances.

Job satisfaction is a complex in which a number of variables are involved. A person may be satisfied with one or more aspects of his/ her job but at the same time may be unhappy with other things related to the job. For example, a TV Anchor/Reporter may be satisfied with his working environment but may not be satisfied with the level of his income and vice-versa.

Almost all studies [2-5] have shown that females possess higher levels of job satisfaction compared to males. This is a puzzling paradox taking into consideration the existence of gender wage differentials in favor of males in some countries, while in some others, women tend to occupy less prestigious jobs and are not likely to be promoted. According to [5], there are a number of theories that explains why females possess higher levels of job satisfaction citing the role of expectations, a possible difference in work 'values' and female selection into employment.

Other scholars also carried out intense study of this phenomenon of gender paradox. The belief that women may be more satisfied because they focus on their roles as homemakers, rather than on their roles as workers, and derives additional satisfactions from this sphere. They compare themselves to other working women and sometimes to housewives rather than men. This kind of comparison gives them a feeling of satisfaction and relief. Hodson and Randy[6], in consistence with others, believes that women may arrive at a higher level of job satisfaction than men by using different comparison groups and adds that men may be more willing to verbalize dissatisfaction with work because of different socialization.

Clark [3] had a different interpretation. He refers to females' lower expectations at work as a reason for their higher levels of job satisfaction which is due to " the poorer position in the labor market that women have held in the past [3]."

Studied gender differences in job satisfaction in different European countries as well as in USA and New Zealand. Both studies reported that females are more satisfied with work compared to males, but differed in interpreting their findings. For pointed to an "'Anglo-Saxon Paradox,' while, who found that females have higher levels of job satisfaction in 10 European countries, did not believe in the "Anglo Saxon Paradox"

*Corresponding author: Hebatalla El Semary, Mass Communication Department UAE University, UAE, E-mail: hebat80@yahoo.com

Received June 25, 2012; Accepted November 29, 2012; Published December 07, 2012

Citation: El Semary H (2012) Perceptions of Job Satisfaction Among Arab Female Reporters in Governmental and Non-Governmental TV Stations. J Mass Commun Journalism 2:135. doi:10.4172/2165-7912.1000135

Copyright: (c) 2012 El Semary H. This is an open-access article distributed under the terms of the Creative Commons Attribution License, which permits unrestricted use, distribution, and reproduction in any medium, provided the original author and source are credited. 
and referred to equal employment opportunities, appropriate childday care and tax and social security system as possible reasons beyond gender job satisfaction differences in three of the countries studied.

A large number of studies have been completed on job satisfaction within the media with varying results. Whilst some studies have shown a strong relation between gender and job satisfaction of media workers $[7,8]$, others have shown that there is no such relation. One consistent finding in almost all studies is that both men and women are satisfied with their jobs as a whole, but there are differences in certain variables related to a job as Serini states:

"The result of the inquiry into job satisfaction, although frequently contradictory, leads to an overall understanding that there are indeed differences between men's and women's levels of satisfaction with a variety of variables related to the work environment."

These variables may include, but not limited to, occupational prestige, earnings, education, job complexity, level of authority exercised. Supervision, job pressure, being held responsible for things outside one's control, promotions, how frequently one has to get dirty on the job, being underemployed. Workplace size, and level of optimism about one's future at the current job [8,9]. In that respect, there are several scales that are used to measure job satisfaction. Two of the most frequently used scales are; "The Job in General (JIG) scale that looks at overall job satisfaction and the Job Descriptive Index (JDI) that looks at five facets of job satisfaction.

Women weigh relations with co-workers more heavily than men and men weigh advancement more heavily than women do. Other studies focused on salary satisfaction and found that women were less favorable on their salary satisfaction scores than men. In the United Arab Emirates (UAE), and despite of equal payments with men, Shallal found females with high incomes are more satisfied with their jobs than those who earn less. Women in occupations such as teaching and administrative work were found to be more satisfied with their jobs than those who do routine office work [10]. Women were also found less satisfied with the amount of work and with the fact that their supervisors are male.

Studies in broadcast media have shown that women in the media face severe problems as a double standard for men and women, unequal promotion opportunities and discrimination on the basis of sex or gender. $[11,12,9]$ found that women are mostly appointed as TV anchors and promotions managers.

As news correspondents, "more women are appearing on evening news broadcasts (ABC, CBS, NBC), but still they are underrepresented compared to men". This was concluded by a twenty-year longitudinal study that examined the patterns of gender diversity in media from years 1983 to 2002. [13] In covering presidential election campaigns (1992-2004), men reporters covering the elections were much more than women, but in terms of productivity, women reported more stories and were "tougher watchdogs" than men [14].

Although significant progress has been made in the last decade concerning women rights and despite the widespread movement towards democratization in most countries, too few women hold key positions in decision-making despite the increased number of women that have entered the labor market. There are many reasons why women are under-represented in decision-making positions. One of these reasons is the media itself as the rigid images it uses are having a damaging effect on women's participation in decision-making positions in political, public life and in the media itself. These obvious underrepresentations of women in decision-making positions in some areas as the media have prevented women from having a significant impact on many key institutions.

Despite the fact that the number of women working in TV news is steadily increasing $(96.8 \%$ of all television news had women on news staffs), the number of women general managers at broadcast stations fell from 17 to 15.2 percent [15]. On the other hand, Creedon concluded a decrease in the percentage of TV news directors in local TV (26.5\%) according to the 2003 statistics revealed by the Radio and Television News Directors Association Survey. She confirmed that this percentage did not increase except by $12.5 \%$ since 1987 [11].

The ASNE survey of 627 journalists at 29 newspapers indicated no significant differences between men and women in terms of job satisfaction. The satisfaction figure was consistent: 67 percent of women, 62 percent of men. The survey indicated that the reasons beyond job satisfaction lie in issues of feedback and decision-making. 36 percent of the satisfied journalists said they got frequent supervisor feedback and 44 percent said they had a voice in news decisions [16] Consistent with these findings, men were slightly more satisfied with their jobs in radio and television than women.

A different study found that women are four times more likely to leave their jobs in journalism than men are [17]. Among those who said they were leaving the media field in the ASNE survey, nearly half said they are dissatisfied with their job because of job-related stress and onethird indicated other reasons as unhappiness with management [16].

Krajicaek [16] analyzed the case of Julia Sandidge, a female TV reporter who was seriously injured when she was punched in the head by a rioter. Julia was left unable to walk for two months and eventually left the daily news business, burdened by stress. She said the assault changed her perspective:

"We'd cover crime and show the video on the news and not take into consideration the victim's family watching that," she told the Star Tribune. "I'd feel grief...I'd go home and cry myself to sleep at night." [16]

Unhappiness with the management could be another reason of dissatisfaction and desire to leave the profession. A survey conducted of 410 women in print news media, shows that women are dissatisfied because of the fewer promotion opportunities and frequently complain of receiving fewer assignments to cover hard news than their male counterparts receive. It was found that women journalists are often asked to cover art and culture or fashion beats. Sexual harassment and age discrimination were reported as other factors "hindering women's upward mobility in their organizations" [18].

Even in reporting sports, women are intensively underrepresented. They form only 12.6 percent of total staffs working in press sports departments and less than 7 percent are columnists at sport staffs [19].

In brief, the literature suggests that despite the widespread movement towards democratization in most countries, too few women hold key positions in the media. It is true that the number of women working in the media is increasing, but still women is underrepresented in some media sectors as reporting sports coverage, covering hard news and decision making positions. The rigid images of women in the media have had a damaging effect on women' performance and have prevented women from having a significant impact on many key institutions. Women are often assigned fashion beats because of their organization's concern that they will not be able to work night shifts. Having children negatively affected their promotion. As a result of all 
of these unequal opportunities, women are no longer satisfied with working in the media and some of them were forced to leave the job. The issue here is critical and could affect the status and position of the industry. In Arab countries, the situation could be even worse, but few studies were interested in discussing the issue. In the UAE, and after the significant increase of women working in the media, especially in television, and particularly after the current trend to localize the media (give priority to employing nationals), job satisfaction among UAE women working in the media becomes an important question to answer taking in to consideration that the comparison between working in governmental and non-governmental TV stations is apparently important. It is worth noting that UAE nationals, in general, prefer working in governmental institutions due to especially cultural and social reasons. This gives this study a new dimension that was not allotted enough concern from other studies.

\section{Purpose}

The prime aim of this study is to find out the Arab Female TV reporters' perception of 'job satisfaction' and to determine the factors which affect job satisfaction of female TV reporters. How ownership and management policy of the TV station could affect job satisfaction among female reporters are among the questions examined in this study.

In this research we sought to determine satisfaction with 15 distinct areas of employment (Company policy, Supervision, Relationship w/ Peers, Relationship w/boss, Work conditions, Salary, Achievement, Recognition, Work itself, Responsibility, Advancement, Growth, Job Security, Work expectations-Decision making) by using two of the most often used survey instruments (Job Descriptive Index and Job In General) that measure job satisfaction.

Although some few perceptions and the factors that affect job satisfaction could be similar to male and female reporters, others are not. These different opinions are mostly interpreted in masculinityfemininity and power distance model of Hofstede [20].

Two-factor theory (also known as Herzberg's motivation-hygiene theory and Dual Factor theory) is another theory which was examined in this study. The Theory was developed by Frederick Herzberg, a psychologist who explains the factors that employees find satisfying and dissatisfying about their jobs. Herzberg called these factors motivators and Hygiene factors.

\section{Herzberg \& Employee Motivation (Figure 1, Table 1)}

Motivators: They are the factors that give positive satisfaction that arises from intrinsic conditions of the job itself (e.g. level of challenge, recognition, work itself, responsibility, advancement, intrinsic interest and opportunities for creativity [21].

Hygiene factors: They are extrinsic to the work itself and do not give positive satisfaction, however, dissatisfaction results from their

\section{Hertzberg's Hygiene Motivation Theory}

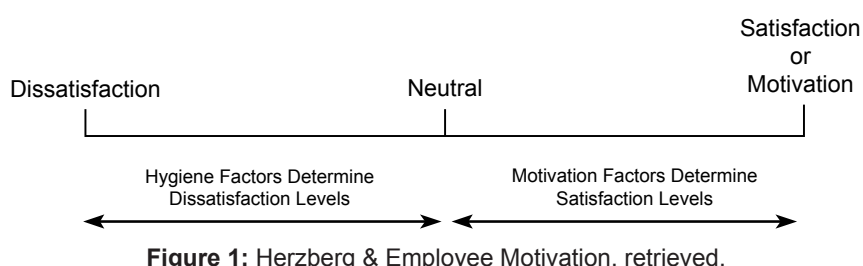

Figure 1: Herzberg \& Employee Motivation, retrieved.

\begin{tabular}{|l|l|}
\hline Leading to Dissatisfaction & Leading to Satisfaction \\
\hline - Company policy & - Achievement \\
- Supervision & - Recognition \\
- Relationship w/Boss & - Work itself \\
- Work conditions & - Responsibility \\
- Salary & - Advancement \\
- Relationship w/Peers & - Growth \\
\hline
\end{tabular}

Table 1: Herzberg \& Employee Motivation, retrieved.

absence (e.g. status, job security, salary, relations with co-workers, job policies, and fringe benefits [22].

Frederick Herzberg rejected the belief that money and other compensation is the most effective form of motivation to an employee and argued that high levels of what he called hygiene factors could reduce dissatisfaction, but not create satisfaction [23]. This was clarified in the following example:

"I need to be paid on time each month so I can pay my bills. If I am not paid on time, I get really unhappy. But when I get paid on time, I hardly notice it. On the other hand, when my boss gives me a pat on the back, I feel good. I don't expect this every day and don't especially miss not having praise all of the time [23]. "

The table 1 below shows the top six factors causing dissatisfaction and the top six factors causing satisfaction according to Herzberg, listed in order (from higher to lower importance)

Factors affecting job attitudes: "Herzberg reasoned that because the factors causing satisfaction are different from those causing dissatisfaction, the two feelings cannot simply be treated as opposites of one another. The opposite of satisfaction is not dissatisfaction, but rather, no satisfaction. Similarly, the opposite of dissatisfaction is no dissatisfaction [24].”

According to Herzberg, management should not only provide hygiene factors to avoid employee dissatisfaction, but should also provide factors intrinsic to the work itself in order for employees to be satisfied with their job [24]. Job satisfaction of Arab female reporters in both governmental and non-governmental TV Stations is the key for achieving the TV station mission, Quality news service, competency, high productivity, and stability.

\section{Methodology}

A total of 200 questionnaires are to be completed by male and female news reporters who are identified as full-time employees of both governmental and Private Arab TV stations (Dubai Media TV channels \& Middle East Broadcasting Center (MBC) TV channels). It is worth mentioning that Dubai Media Incorporated (DMI) was established in 2003 as the official media organization of the government of Dubai. It is composed of a number of print, radio and TV channels including: Dubai TV, Al Bayan, Sama Dubai, Dubai One, Dubai Sports, Dubai Racing, Noor Dubai Radio \& TV, Dubai FM, Emarat Al Youm, Emirates 24/7, Tawseel and Masar Printing Press [25]. Middle East Broadcasting Center (MBC) is a pan-Arab, news and entertainment broadcaster that was launched in 1991 as the first privately owned and independent Arabic satellite TV station. It was founded in London, and was then transferred to Dubai in 2000. MBC was set up by two private entrepreneurs, one of whom, Shaikh Walid al-Ibrahim. It owns ten TV channels, including MBC1, MBC2 and MBCMAX.in addition to two radio stations [26].

Fredrick Herzberg's two factor theory, power distance, and masculinity-femininity theory of Hofstede have been chosen to analyze data as well as variables. 
Moreover, In-depth interviews were conducted with 10 news personnel in governmental and non-governmental TV Stations to enrich the quantitative data with qualitative evidence.

The study is an empirical research and is to be done by using the quantitive and qualitive approach of research. It uses full variety of evidence documents, artifacts and interviews to explain and test assumptions concerning casual relations among variables under investigation.

\section{Data collection}

200 questionnaires were distributed via e-mail among newsmen and newswomen in the two selected governmental and non-governmental TV stations. First time, only 26 filled questionnaires were received. Two reminders, with an interval of two weeks, were sent to the nonrespondents. In all 107 filled questionnaires were received. Out of these seven were dropped because of being incomplete. Therefore, the final count stood at 100.Information about sex, age, qualification, year of qualification, type of TV Station (governmental or nongovernmental), marital status, designation, monthly income, private practice, satisfaction with income/work conditions/Company policy/ relationship with Peers/Supervision/relationship with boss/decision making/Achievement/Job Security/Work expectations? Recognition/ Responsibility/Growth/Advancement/work itself) was collected.

Monthly income was measured on 5-point scale from 1 . Job satisfaction with respect to Salary, Advancement, work conditions availability of equipment facilities, amount of work), Supervision, Relationship with boss, Relationship with Peers, Job Security, Work expectations, decision making were measured on four point scale from $1=$ not satisfied to $4=$ very much satisfied.

Percentages, means, standard deviations and correlation (Spearman's ratio) were used to identify the factors significantly related with job satisfaction or dissatisfaction. The p-values of 0.05 and 0.01 were used as the level of significance. SPSS version 10.0 was used for statistical analysis.

\section{Research hypothesis}

1. TV Newswomen with lower work expectations possess higher job satisfaction levels compared to Newsmen with lower work expectations.

2. Newswomen in governmental TV stations possess higher job satisfaction levels than their counterparts in nongovernmental TV Stations.

3. TV Newswomen in decision-making positions possess higher job satisfaction than their counterparts in traditional positions.

4. TV Newswomen possess higher job satisfaction levels when they are chaired by a woman than when they are chaired by a Man.

5. TV newswomen with high income possess higher job satisfaction levels than TV newsmen with high income.

6. TV Newswomen in good working environment possess higher job satisfaction levels than TV Newsmen in similar working conditions.

\section{Results/Findings}

1. The data indicates that Newswomen have lower expectations toward the job than their male counterparts. This could be due to the fact that TV News is a male dominated workplace, that's why females' expectations of the job are low in comparison to males. It is found that TV Newswomen with lower work expectations possess higher job satisfaction compared to their male counterparts. T-test shows that there are significant differences between males and females in that respect which leads us to accepting the first hypothesis in this study.

2. The level of Job satisfaction in governmental TV stations is higher than non-governmental TV. And in Dubai TV higher than MBC. In general, Locals or Emiratis news personnel feel more secure in governmental than non-governmental stations. Pensions and promotional opportunities are among reasons of high job satisfaction levels at governmental TV stations among locals. In terms of Job security, non-locals prefer non-governmental TV stations. At least, they are confident they won't be replaced by a local. T-test shows that there are significant differences between Newswomen working in governmental and non-governmental TV stations in regard to the level of job satisfaction. This makes us accept the second hypothesis in this study.

3. TV newswomen generally respond more favorably on survey items regarding overall Job Satisfaction (52\%), but there are no significant differences between males and females in that respect. Interestingly, newsmen tend to respond more favorably when asked if they felt included by their supervisor in decisions affecting them and whether senior management was concerned for employees.

4. TV decision making Newswomen possess higher levels of job satisfaction than TV newswomen in traditional positions as anchors, editors and reporters. T-test results show that the differences between the two groups in that respect are significant. This leads us to accept the third hypothesis in this study.

5. The data indicates that $72 \%$ of TV newswomen prefer to be chaired by men than by women. In that respect, Newswomen believe that men are better in leading or decision making positions than women especially in male dominated workplaces. The differences in that respect proved to be significant meaning that we have to accept the fourth hypothesis in this study.

6. Overall, $56 \%$ of TV Newswomen were not satisfied and only $10 \%$ is very much satisfied with the level of their income. Among those very much satisfied, $60 \%$ are those holding Mass Comm. bachelor degree. Among those having Masters Degree, 65\% are not satisfied with the level of their income. Among PH D holders 70.59\% are not satisfied with the level of their income, whereas only $20 \%$ of those working as TV Newswomen above are not satisfied with the level of income.

7. It is true that there are equalities in salary pay between women and men in the Arab World, but there are differences in the total income. Many of the TV News personnel are allowed to work on part time basis in other TV stations or in advertisements to increase their income. Findings reveal that TV newswomen with high income (52\%) possess higher job satisfaction levels than TV newsmen with high income (49\%).The differences between the two groups in that respect proved to be insignificant. That's why we don't have to accept the fourth hypothesis in this study.

8. Consistent with past studies that have found gender job satisfaction differences disappear for the younger and highly educated, we found that younger females are still more satisfied at work compared to males in three of the measures investigated. However, higher educated females are only more satisfied with higher educated males with respect to pay, and are actually less satisfied with hours worked and amount of work.

9. It is found that both the male and female TV News personnel 
are dissatisfied but the female section is more dissatisfied than those of the male TV personnel.TV newswomen are dissatisfied with working hours, decision making \& promotional opportunities. This result could be explained as relevant to the Arab Culture that believes in males capabilities in hard work and decision making positions.

10. It is found that, $48 \%$ of the TV reporters are not satisfied with their working environment and out of these $83.33 \%$ are bachelor degree holders. Only $6 \%$ are really satisfied with their working environment. Among those working as in leading positions as chief-editors, head of TV News departments or above, $20 \%$ are not satisfied with the working environment.

11. Findings also reveal that working environment is among the factors that affect job satisfaction. TV Newswomen in good working environment (69\%) possess higher job satisfaction levels than TV Newsmen in similar working conditions (39\%). The differences between the two groups in that respect proved to be significant. That's why; we have to accept the sixth hypotheses in this study.

12. Overall, $78 \%$ of the TV News reporters would like to serve in another TV station. Only $12 \%$ of them are females and all of them are locals. This shows that females in general tend to keep their jobs no matter what problems they face.

13. Results show that the TV News personnel were most satisfied with working environment (1.67) and equipment facilities (1.67) while income level (1.22) turned out to be among the factors causing dissatisfaction especially with the continuous rise in rents and housing in Dubai and Abu Dhabi.

14. Female TV reporters who proved to be effective in work through their achievements and were recognized by their supervisors for their accomplishments posses higher levels of job satisfaction than their male counterparts. T-test results showed significant differences in that respect.

\section{Conclusion}

This study confirmed findings of the aforementioned studies as 52\% of female news reporters posses overall higher levels of job satisfaction than males, although it turned out to be that there are no significant differences between males and females in that respect.

Advancement, Supervision and Growth were found among factors causing job satisfaction among female news reporters, while income, Job security, company policy/ownership were found to be among factors causing dissatisfaction. These findings provide evidence to the ideas raised by Herzberg in his motivation/hygiene theory.

We disagree with Herzberg in different aspects, one of which is work conditions that were found to be a factor affecting job satisfaction rather than dissatisfaction.

Our study also points out to the fact that Motivation/hygiene theory did not take into consideration individual differences as well as intervening factors that affect job satisfaction/dissatisfaction such as a particular personality traits, which would affect individuals' unique responses to motivating or hygiene factors. In that respect, we cite for mention age, gender and education.

Regarding job security, it is quite clear that non-locals feel unsecure in governmental TV stations as they could be replaced any time if there is an available well qualified local TV reporter, while locals feel unsecure in non-governmental TV stations. This policy is applied in all governmental institutions, not only TV stations, as part of an overall policy of emiratization to resolve unemployment problems among locals.In that respect, Abu Dhabi Tawteen Council (ADTC) was established in December 2005 to ensure that the Emirati becomes the first choice of employment in Abu Dhabi (Abu Dhabi Tawteen Council) [27].

One of the striking results in this study is that female news reporters prefer to be supervised by a man not by a woman. They confirm that their relationship with a male boss is much better than a female boss. $31 \%$ of Female news reporters insist that discrimination in work takes place only when the boss or decision maker is a woman. This, in my opinion, could be explained in terms of fear to be accused of bias. Women in male dominated work place like TV News, try their best to prove effective, competitive and objective. This turns to be against women employers in many ways.

Herzberg argues that employees, who demonstrate increasing levels of ability should be given increasing levels of responsibility, but in this study $34 \%$ of female news reporters mainly working as correspondents, revealed that their job responsibilities do not use their full abilities while their male counterparts (78\%) expressed high levels of satisfaction with their responsibilities. This is considered another face of discrimination but this time coming from management of the TV station. The director of the News Center in Dubai TV believes that working as correspondents fits men more than women especially among the local community. Local families won't permit their daughters to work in conflict countries like Palestine alone even if they are under direct supervision. This means that we need to launch media campaigns to spread awareness among the local community on the importance of women' role in covering news.

Moreover, work expectations, decision making positions were found to be one of the factors affecting job satisfaction especially among women in male dominated work place as TV News. This factor could be added to the list of motivators mentioned by Herzberg.

Despite of all, Herzberg's theory is still regarded a good indicator of job attitudes although job satisfaction does not necessarily imply a high level of motivation or productivity.

\section{References}

1. Clark A, Oswald A, Warr P (1996) Is job satisfaction U-shaped in age? Journal of Occupat-ional and Organtzat-ional Psychology 9: 57

2. Glenn ND, Pamcia AT, Charles NW (1977) Age and job satisfaction among males and females: A multivariate, multi-survey study. Journal of Applied Psychology 62: 189-193.

3. Clark A (1997) Job satisfaction and gender: Why are women so happy at work? Labor Economics 4: 341-372

4. Kifle, Kler (2007) Job Satisfaction and Gender: Evidence from Australia.

5. Kifle \& Kler (2011) Are Women Really That Happy at Work? Australian Evidence on the 'Contented Female'.

6. Hodson, Randy (1989) Gender differences in job satisfaction: Why aren't women more dissatisfied. The Sociological Quarterly 30: 385-399.

7. Grunig L, Toth E, Hon L (2001) Women in Public Relations. New York, New York: The Guilford Press.Hill, G \& Hill, K. Law.com Dictionary. Obtained December 12, 2003, from the World Wide Web: www.law.com.

8. Barrett G (1984) Job satisfaction among newspaperwomen. Journalism Quarterly 61: 593-599.

9. Irani T, McGovney, Rebecca L ( 2005) Perceptions of Job Satisfaction and Gender Roles Among Select Florida Agricultural Communication Practitioners.

10. Shallal, Musa (2011) Job satisfaction among women in the United Arab Emirates. Journal of International Women's Studies 12: 3 . 
Citation: El Semary H (2012) Perceptions of Job Satisfaction Among Arab Female Reporters in Governmental and Non-Governmental TV Stations. J Mass Commun Journalism 2:135. doi:10.4172/2165-7912.1000135

11. Creedon $P$ (1989) Women in mass communication challenging gender values. Newbury Park, California: SAGE Publications, Inc.

12. Jamieson K (2001) Progress or No Room at the Top? The role of women in telecommunications, broadcast, cable and e-companies.

13. The Commission on the Status of Women (2005) Women Corresponden Visibility on Network Television News-A Twenty Year Longitudinal Study. Association for Education in Journalism \& Mass Communication.

14. Grabe ME, Samson L, Zelankauskiate A, Yegiyan N (2011) Covering presidential election campaigns: Does reporter gender affect the work lives of correspondents and their reportage? Journal of Broadcasting \& Electronic Media 55: 285-306.

15. Papper B ( 2006) "RTNDA/Ball State University Annual Survey of women and minorities in the newsroom." Communicator. July/August.

16. Krajicaek, Dave (2010) Covering Crime and Justice.

17. Bhagat, Pamela (2004) Status of women journalists in the print media.

18. Carnahan W (2000) A Brief History of ACE. Journal of Applied Communications 84: 7-19.
19. Media Management Center at Northwestern University (2006) Women in the Media 2006: Finding the leader.

20. Tasnim S (2006) Job satisfaction among female teachers: a study on primary schools in Bangladesh, a M.Phil. thesis submitted to the department of Administration and Organization Theory ,University of Bergen, Norway.

21. Hackman JR, Oldham GR (1976) Motivation through the design of work: Test of a theory. Organizational behaviour and human performance 16: 250-279.

22. Herzberg F, Mausner B, Snyderman BB (1959) The Motivation to work. John Wiley. New York.

23. Jex SM, Britt TW (2008) Organizational psychology. Hoboke, New Jersey, USA: John Wiley \& Sons, Inc.

24. Internet Center for Management and Business Administration (2002) Herzberg's motivation-hygiene theory inc.

25. Sakr, Naomi (2001) "Whys and Wherefores of Satellite Channel Ownership". Satellite Realms: Transnational Television, Globalization and the Middle East.

26. "Arab Media Outlook. 2008-2012". Dubai Press Club. http://www.pwc.com/gx/ en/entertainment-media/pdf/arabmediaoutlook.pdf. Retrieved May 19, 2012

27. Abu Dhabi Tawteen Council (ADTC) 2012 